\title{
Compilación del patrimonio monumental, casonas e iglesias de la provincia de Arequipa
}

\section{Compilation of Monumental Tourist Patrimony, Ancient Houses and Churches of the Province of Arequipa}

\author{
Mappy Arce Figueroa*, Manuel Linares Pacheco**, \\ Luis Delgado Barreda***
}

http://dx.doi.org/10.21503/CienciayDesarrollo.2006.v7.09

\section{RESUMEN}

Esta investigación tiene carácter metodológico y es de trascendencia local y nacional. Es asimismo una investigación viable porque se cuenta con los recursos humanos, económicos y materiales para su ejecución. La labor de trascripción de los datos obtenidos en las fichas de trabajo es lo que consideramos de mayor importancia, toda vez que ha permitido una exitosa selección del material censado.

Hemos cumplido de esta manera con uno de los objetivos del gobierno regional, cual es el de registrar documentalmente el patrimonio monumental (casonas e iglesias) de la provincia de Arequipa y sus distritos.

Palabras clave: patrimonio monumental, centros históricos, arquitectura religiosa.

\section{ABSTRACT}

This investigation has a methodical original and transcendent characteristic: it is a feasible research because we have an excellent human, economic and material resource, to do it. The task of data transcription from the work sheets it is what is most relevant, because they allow a successful selection of censed material.

Fulfilling this way one of the objectives of the Regional Government, this is to register meticulously the compilation of Monumental Patrimony (churches and ancient houses) in the Province of Arequipa and of course its districts.

Key words: monumental patrimony, historical centers, religious architecture.

\footnotetext{
"Directora Adjunta de la Escuela de Turismo, Hotelería y Gastronomía. Universidad Alas Peruanas, filial Arequipa.

"Docente de la Universidad Alas Peruanas, filial Arequipa. E scuela Profesional de Turismo Hotelería y Gastronomía.

*.* Docente de la Universidad Alas Peruanas, filial Arequipa. E scuela Profesional de Turismo Hotelería y Gastronomía.
} 


\section{INTRODUCCIÓN}

Después de los violentos años de la conquista, el Perú se convirtió en una de las principales fuentes de abastecimiento de materias primas de la corona española, y sus recursos atrajeron a miles de europeos, especialmente a frailes misioneros que, en su afán evangelizador, alteraron en la forma, aunque no siempre en el contenido, las creencias, los rituales, la música, la vestimenta y el aspecto de los nacientes centros urbanos. Como consecuencia de la imposición de este nuevo orden civil, militar, religioso y cultural, surgieron las grandes ciudades señoriales como Lima, Cusco, Arequipa, Trujillo, Ayacucho y Cajamarca. Fue así que la forma física de las ciudades fue cambiando, de manera que poco a poco se fueron creando los centros urbanos cuya característica común era la presencia de los típicos "dameros", es decir, un grupo de manzanas cuadradas o rectangulares dispuestas alrededor de una plaza principal. Todas las ciudades iban creciendo bajo ese mismo esquema.

A lo largo y ancho del territorio nacional se conservan centros históricos de gran importancia, pues constituyen muestra evidente de la influencia de la conquista española en nuestro país.

En la actualidad, la Dirección de Centros Históricos, a través de la Dirección General de Patrimonio Monumental e Histórico del Instituto Nacional de Cultura, y las Municipalidades se encargan de velar por la conservación de los centros históricos. Es necesario señalar también que algunos de ellos han merecido el reconocimiento de Patrimonio Cultural de la Humanidad. Tales son los casos del Centro Histórico de Arequipa, el Centro Histórico del Cusco y el Centro Histórico de Lima.

$\mathrm{Al}$ igual que las zonas monumentales, los ambientes urbanos monumentales son numerosos en nuestro país. Generalmente, las plazas princi- pales de cada departamento han sido reconocidas como tales, constituyéndose en focos urbanos de gran relevancia no sólo por sus calles y avenidas, sino también por la arquitectura que las delimita. Es el caso de la Plaza Mayor de Lima, declarada Ambiente Urbano Monumental por Resolución Suprema No. 2900-72-ED del 28-12-72. Esta plaza, antiguamente llamada Plaza de Armas, fue el escenario donde Francisco Pizarro fundó la ciudad de Lima, el 18 de enero de 1535. La plaza ha sufrido muchas transformaciones, al punto que lo único verdaderamente virreinal que queda en ella es la añeja pileta de bronce ubicada en el lugar donde antaño un pilón de agua satisfacía las necesidades de los primeros habitantes de Lima. Las construcciones que la circundan tienen un estilo neocolonial barroco. Es importante señalar que lo mismo sucede con la Plaza de Armas de Arequipa y la Plaza de Armas del Cusco, por ejemplo.

Existen también los monumentos históricos artísticos, rubro bajo el cual se agrupan las edificaciones que conforman la infraestructura urbana. Hay que señalar, asimismo, que no existe departamento en el que no se hayan declarado edificaciones con la condición de monumentos.

Para un mejor ordenamiento, las construcciones monumentales se han dividido, según su función, en:

- Arquitectura religiosa. Destacan en este rubro la Catedral, las iglesias de San Francisco, Santo Domingo, San Pedro, La Merced, San Agustín, San Marcelo, Las Nazarenas, Santa Rosa, en Lima. En Arequipa son dignos de mencionar los monasterios de Santa Teresa, Santa Catalina y las iglesias de San Francisco, la Merced, Santo Domingo, la Recoleta, de la Compañía y San Agustín.

- Arquitectura militar. Conformada por construcciones realizadas por la Corona Española en el Perú y por edificaciones levantadas durante los 
primeros años de la república, entre los que se tiene: el Sector "A" del Cuartel de Barbones, el Cuartel de Santa Catalina, el local de la Antigua Escuela Militar de Chorrillos, la Fortaleza del Real Felipe, en Lima.

- Arquitectura pública. Son las edificaciones que sirvieron de vivienda a las familias adineradas de esa época, y que en la actualidad son utilizadas como sedes de organismos públicos o privados. Ejemplos son, en este caso, la Casa de Pilatos, el actual Local del Tribunal Constitucional, la Casa y Palacio de Torre Tagle, así como también el Palacio de Gobierno, el Palacio de Justicia, la Municipalidad de Lima, el local del Congreso, la Biblioteca Nacional, la Casona de San Marcos, la Casa de la Moneda, entre otros, todos ellos en la Capital. En Arequipa tenemos La Casa del Moral, la Mansión del Fundador, el Fundo del Padre Fierro y las casonas que hoy ocupan instituciones bancarias como la Casa Tristán del Pozo o la Casa Riccketts o Ugarteche (Banco Continental), la Casa Goyeneche (Banco de Reserva del Perú).

- Arquitectura civil. Comprende a las construcciones edificadas por familias importantes de la sociedad peruana durante la colonia y la república. Las principales muestras de este tipo de arquitectura son el denominado Club de La Unión en Lima, el Club Arequipa en Arequipa. Están también en este grupo la Casa Oquendo o Palacio de Osambela, la Casa Aspíllaga, la Casa de los Marqueses de la Riva Agüero, la Casa Barbieri o de los Condes del Villar, la Casa y Capilla de la antigua hacienda San Isidro y la Casa de Aliaga, en Lima. En Arequipa están la Casa Goyeneche, la Casa Mendiburu, la Casa Irriberry o Casa Arróspide, la Mansión del Fundador, la Casa de la Familia Muñoz Nájar, la Casa de Silvia (la musa de Melgar), la Casa del Cacique Alpaca, la Casa Bustamante, etc. Hay que resaltar, en este punto, que algunas de estas edificaciones pertenecen hasta la actualidad a los descendientes del propietario original. Cuentan con un gran valor arquitectónico, además del histórico-monumen- tal, pues presentan una construcción en varios planos, incluso bajo el nivel del piso; además, la ubicación de la escalera en el mismo centro del zaguán aparta su fisonomía del patrón clásico de la típica casona.

Las construcciones consideradas monumentos históricos, así como las casonas e iglesias en su conjunto, han sufrido graves alteraciones por la falta de identificación y compromiso con el patrimonio, tanto por parte de la población como de las autoridades, para no mencionar ya los terremotos que ha tenido que soportar nuestra ciudad las demoliciones de que han sido objeto muchas de ellas por parte de los dueños. De otro lado, frente a las modificaciones y construcciones clandestinas en el propio centro de la ciudad, el Instituto Nacional de Cultura, en coordinación con las municipalidades, viene realizando la evaluación de los proyectos de remodelación, adecuación y modificación, con el fin de mantener el aspecto original de los espacios y la infraestructura de las casonas e iglesias.

Consciente de la necesidad de adquirir una visión global de los inmuebles monumentales de la provincia de Arequipa en toda su variedad, la Escuela de Turismo, Hotelería y Gastronomía ha considerado trascendente la realización de esta compilación del patrimonio monumental de la provincia de Arequipa, casonas e iglesias. En realidad, esta compilación pretende aportar a la cultura una guía manual que sirva a todas aquellas personas o turistas interesados en su conocimiento.

La compilación del Patrimonio Monumental Nacional se basa en una política de conservación de la herencia cultural de nuestro país, política que promueve el conocimiento de su tipología, de su antigüedad y de la época histórica a la que pertenece este patrimonio, además de establecer su relación con eventos o personajes de trascendencia local o nacional y determinar su pertenencia espacial y temporal. 
Todo lo anterior implica, necesariamente, el registro de aquellos bienes tangibles (bienes muebles) cuya evidencia táctil y visual indica que merecen conservarse porque constituyen testimonio material de la evolución de nuestra sociedad.

\section{Objetivos}

\section{Objetivo general}

$\checkmark$ Conocer y difundir la magnitud del Patrimonio Cultural Monumental de la provincia de Arequipa, promoviendo su conservación.

\section{Objetivos especificos}

$\checkmark$ Conocer la tipología, antigüedad y época histórica a la que pertenece el Patrimonio Cultural Monumental de Arequipa.

$\checkmark$ Conocer la relación de este patrimonio con eventos o personajes de trascendencia local o nacional.

$\checkmark$ Fortalecer el espíritu nacional, el mismo que sustenta nuestra identidad cultural local.

$\checkmark$ Registrar el Patrimonio Monumental de la provincia de Arequipa y sus distritos,

$\checkmark$ Conservar y defender el Patrimonio Monumental de la provincia de Arequipa y sus distritos.

\section{MATERIAL Y MÉTODOS}

La metodología propuesta para la presente compilación se enmarca dentro de un programa metodológico mixto, histórico y cultural, por las características de trabajo a realizarse en los aspectos temporal y geográfico.

\section{Patrimonio inventariado}

El Patrimonio Monumental a inventariarse debe pertenecer a la arquitectura desarrollada desde la fundación de la ciudad, en el siglo XVI, hasta las primeras décadas del siglo XX, lo que implica una cobertura del Patrimonio Monumental Virreinal y Republicano.

\section{Área de trabajo}

La presente compilación ha tomado como área de trabajo el Centro Histórico de Arequipa, cuya conservación está amparada por la R.S. 2900-72-ED del 23/12/1972. Esta resolución establece un gran número de monumentos históricos, comprendidos entre los siguientes límites: el cauce del río Chili entre la Av. Salaverry y la torrentera de San Lázaro, la prolongación de la calle Peral, la prolongación Ayacucho, la calle San Pedro, la Calle Manuel Muñoz Nájar, la Av. Goyeneche y la Av. Jorge Chávez y calles inmersas. Además, han sido condiderados todos los distritos de Arequipa (se adjuntan planos).

\section{Jerarquía de valores}

En la determinación de los inmuebles que deben ser incorporados a esta compilación se deben tener en cuenta las siguientes consideraciones, basadas todas en principios de conservación:

C1. Relación con la historia, arqueología, arquitectura, urbanismo o el conocimiento científico en general de la ciudad de Arequipa.

C2. Particularidades del período histórico, modalidad constructiva, estilo arquitectónico y su importancia en el entorno, así como también aquellas vinculadas con los aspectos artístico, técnico o documental.

C3. La no existencia de otra obra de similares características.

C4. Los valores intrínseco, estético y visual que contribuyen a la construcción del carácter tradicional de la arquitectura arequipeña.

C5. Una antigüedad no menor a 100 años. 


\section{Prioridades en la selección de inmuebles}

Es preciso tener en cuenta lo siguiente:

a) Su pertenencia a ambientes monumentales, de preferencia declarados como tales, a fin de coadyuvar a su conservación.

b) Su ubicación en lugares que registren la mayor concentración de inmuebles no declarados como Monumentos Históricos.

c) Las amenazas de demolición total, mutilación o deterioro.

d) Haber merecido estudios o atención especial por parte de las instituciones o personas en los últimos años.

e) El daño recibido por los terremotos producidos en nuestra ciudad.

\section{Documentación bibliográfica}

Se deben utilizar los siguientes archivos o depositarios del patrimonio cultural: a) Archivo del Instituto Departamental de Cultura de Arequipa, constituido por planos, dibujos, documentos, expedientes técnicos, etc.

b) Planos del Museo Histórico Municipal, así como fotografías, planos, mapas, etc.

c) Bibliografía referida a las características de la arquitectura arequipeña.

d) Pautas y normas nacionales e internacionales sobre el inventario de bienes inmuebles.

e) Registro documental de la SUNARP (legajos).

f) Leyes.

g) Listado de los inmuebles que constituyen la herencia monumental del distrito, el mismo que forma parte de la documentación de las municipalidades correspondientes.

h) Consultas a especialistas: arqueólogos, historiadores, autoridades, arquitectos, diseñadores, etc.

\section{Cronograma de realización}

\begin{tabular}{|c|c|c|c|c|c|c|}
\hline ACTIVIDADES & $\begin{array}{l}\text { Mayo } \\
10-30\end{array}$ & $\begin{array}{c}\text { Junio, julio, agosto } \\
4-30-30\end{array}$ & $\begin{array}{l}\text { Sept. } \\
3-28\end{array}$ & $\begin{array}{c}\text { Octubre } \\
1-31\end{array}$ & $\begin{array}{l}\text { Nov. } \\
2-30\end{array}$ & $\begin{array}{l}\text { Dic., Enero } \\
1-30\end{array}$ \\
\hline 1. Elaboración del plan & $\mathrm{X}$ & & & & & \\
\hline $\begin{array}{l}\text { 2. Digitalización del } \\
\text { instrumento }\end{array}$ & $\mathrm{X}$ & & & & & \\
\hline $\begin{array}{l}\text { 3. Aplicación del instrumento } \\
\text { y fotografiado }\end{array}$ & & $\mathrm{X}$ & & & & \\
\hline $\begin{array}{l}\text { 4. Compilación del } \\
\text { Patrimonio Monumental } \\
\text { fotografiado }\end{array}$ & & & $\mathrm{X}$ & & & \\
\hline $\begin{array}{l}\text { 5. Procesamiento de la } \\
\text { información }\end{array}$ & & & & $\mathrm{X}$ & & \\
\hline $\begin{array}{l}\text { 6. Elaboración del informe } \\
\text { final }\end{array}$ & & & & & $\mathrm{X}$ & \\
\hline 7. Imprevistos $25 \%$ & & & & & & $\mathrm{X}$ \\
\hline $\begin{array}{l}\text { 8. Sustentación / exposición } \\
\text { del informe }\end{array}$ & & & & & & $\mathrm{X}$ \\
\hline
\end{tabular}


Hoja de ruta

UNIVERSIDAD ALAS PERUANAS

ESCUELA DE TURISMO, HOTELERÍA Y GASTRONOMÍA

Ficha $\mathrm{N}^{\circ}$

\begin{tabular}{|c|c|c|c|c|c|c|}
\hline $\mathrm{N}^{\circ}$ & Calle & $N^{o}$ de Casa & $\mathrm{N}^{\circ}$ Imagen & Referencia & Observaciones & Censador \\
\hline \multicolumn{7}{|l|}{1} \\
\hline \multicolumn{7}{|l|}{2} \\
\hline \multicolumn{7}{|l|}{3} \\
\hline \multicolumn{7}{|l|}{4} \\
\hline \multicolumn{7}{|l|}{5} \\
\hline \multicolumn{7}{|l|}{6} \\
\hline \multicolumn{7}{|l|}{7} \\
\hline \multicolumn{7}{|l|}{8} \\
\hline \multicolumn{7}{|l|}{9} \\
\hline \multicolumn{7}{|l|}{10} \\
\hline \multicolumn{7}{|l|}{11} \\
\hline \multicolumn{7}{|l|}{12} \\
\hline \multicolumn{7}{|l|}{13} \\
\hline \multicolumn{7}{|l|}{14} \\
\hline \multicolumn{7}{|l|}{15} \\
\hline \multicolumn{7}{|l|}{16} \\
\hline \multicolumn{7}{|l|}{17} \\
\hline \multicolumn{7}{|l|}{18} \\
\hline \multicolumn{7}{|l|}{19} \\
\hline \multicolumn{7}{|l|}{20} \\
\hline \multicolumn{7}{|l|}{21} \\
\hline 22 & & & & & & \\
\hline 23 & & & & & & \\
\hline 24 & & & & & & \\
\hline 25 & & & & & & \\
\hline 26 & & & & & & \\
\hline 27 & & & & & & \\
\hline 28 & & & & & & \\
\hline 29 & & & & & & \\
\hline 30 & & & & & & \\
\hline 31 & & & & & & \\
\hline 32 & & & & & & \\
\hline 33 & & & & & & \\
\hline 34 & & & & & & \\
\hline 35 & & & & & & \\
\hline 36 & & & & & & \\
\hline 37 & & & & & & \\
\hline 38 & & & & & & \\
\hline 39 & & & & & & \\
\hline 40 & & & & & & \\
\hline 41 & & & & & & \\
\hline 42 & & & & & & \\
\hline 43 & & & & & & \\
\hline 44 & & & & & & \\
\hline 45 & & & & & & \\
\hline 46 & & & & & & \\
\hline 47 & & & & & & \\
\hline 48 & & & & & & \\
\hline
\end{tabular}


Ficha de trabajo

\section{Censo del Patrimonio Arquitectónico de Arequipa}

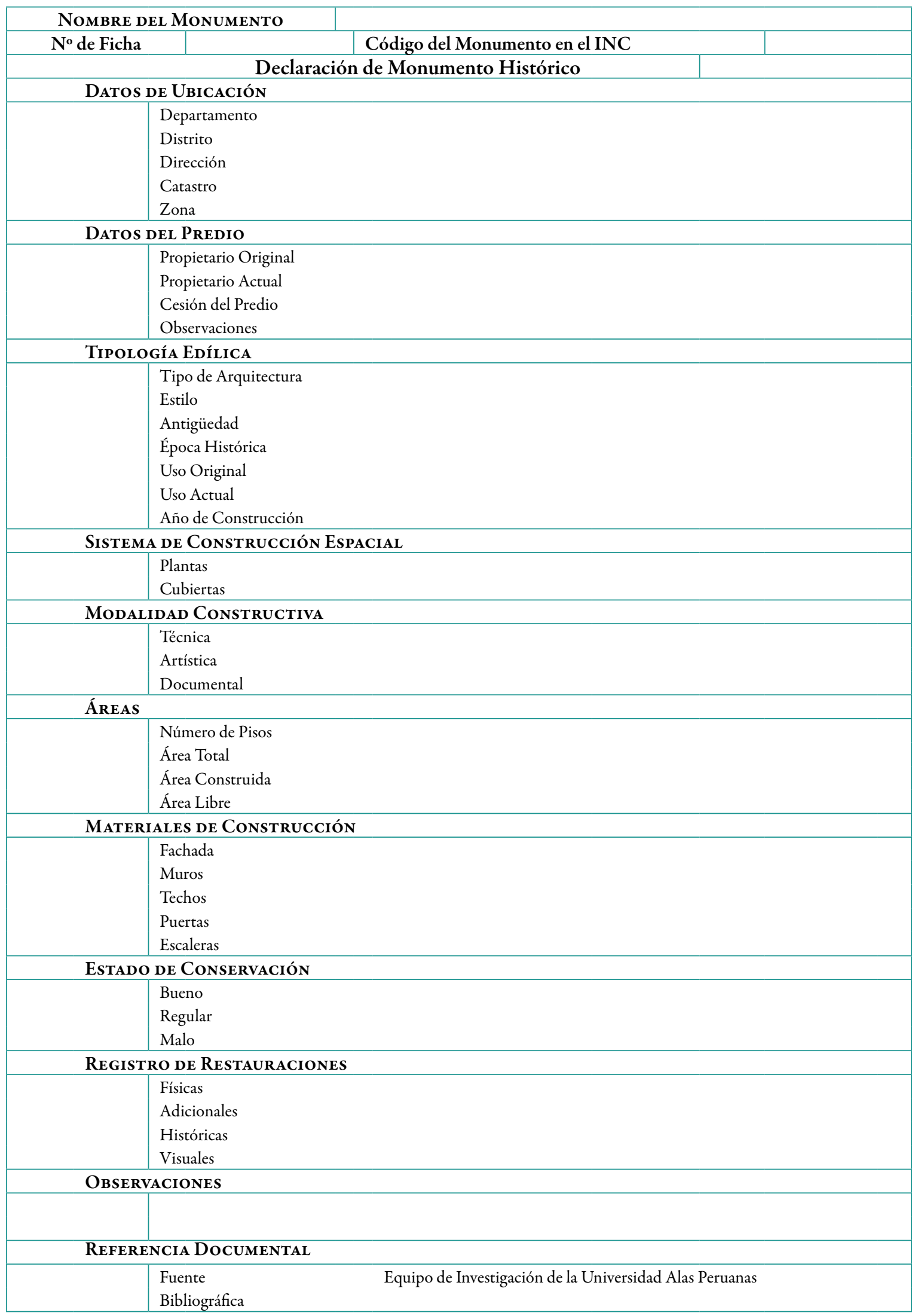




\section{RESULTADOS}

\section{LA CATEDRAL DE AREQUIPA}

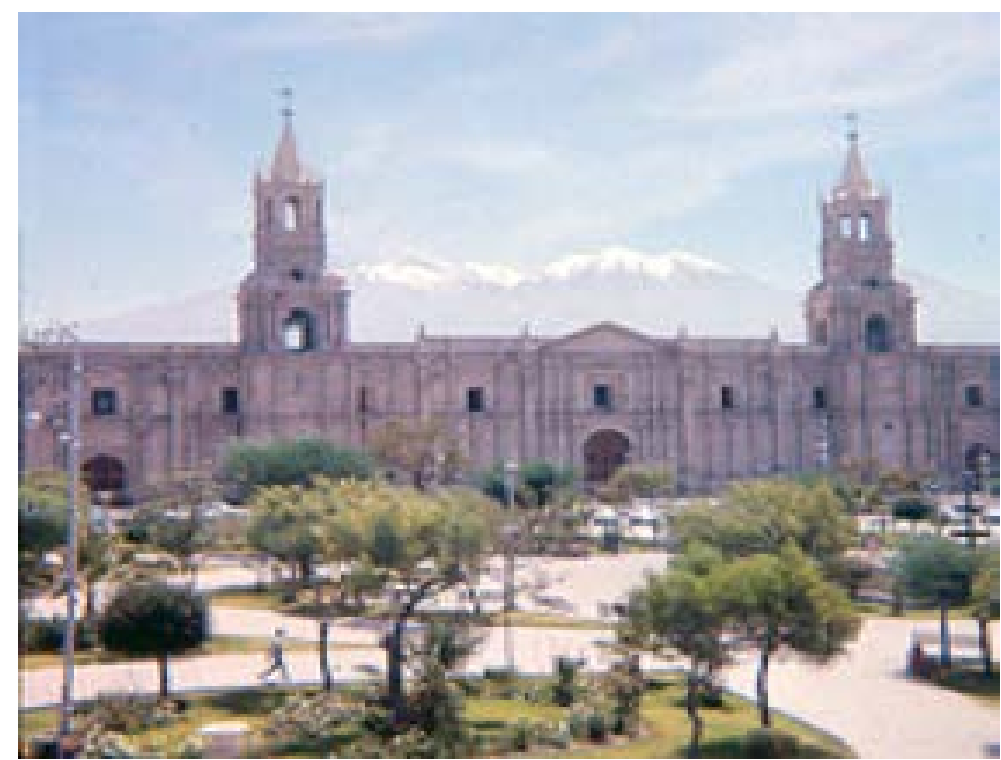

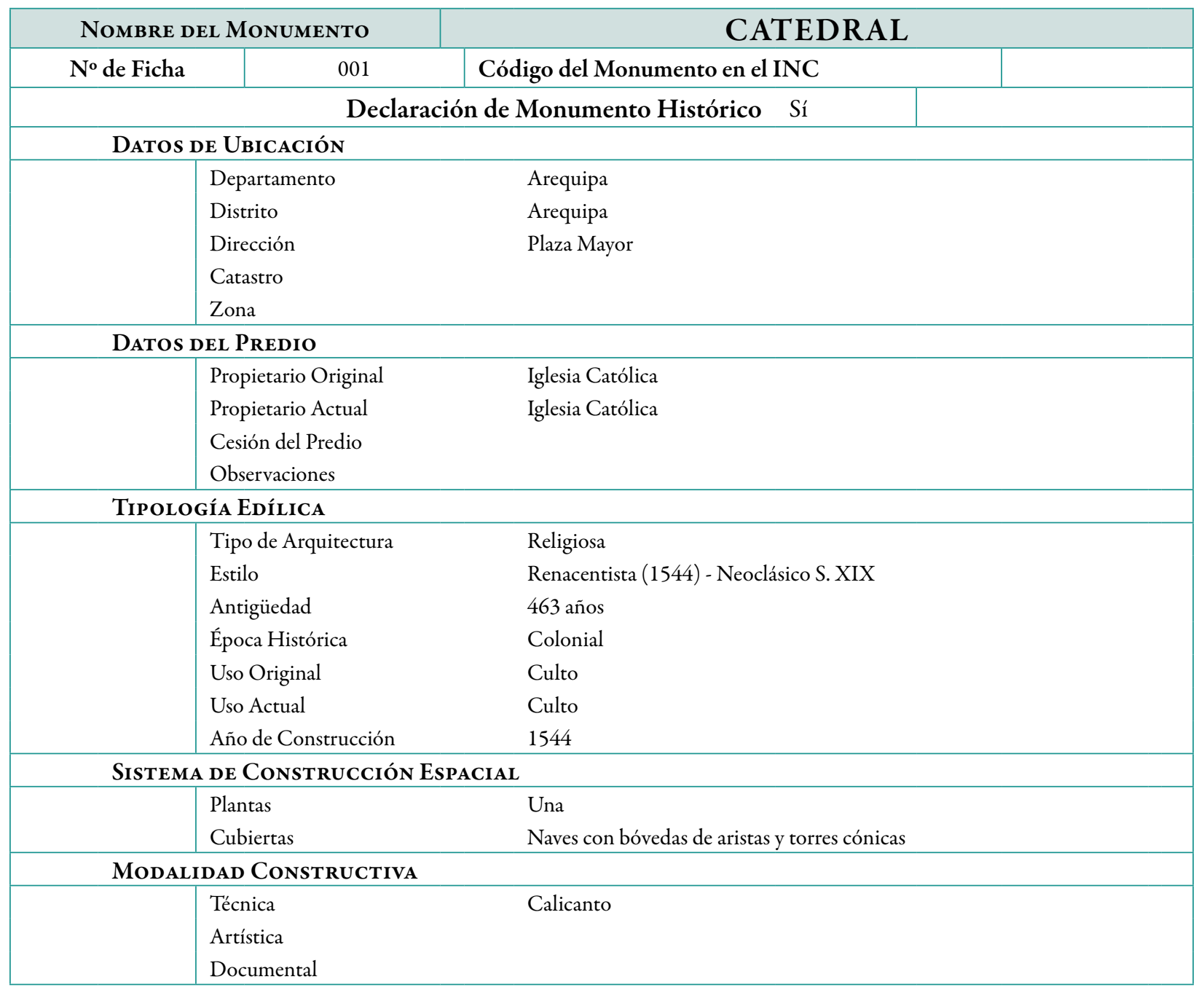




\begin{tabular}{|c|c|c|}
\hline \multicolumn{3}{|l|}{ ÁrEAS } \\
\hline & $\begin{array}{l}\text { Número de Pisos } \\
\text { Área Total } \\
\text { Área Construida } \\
\text { Área Libre }\end{array}$ & Uno \\
\hline \multicolumn{3}{|c|}{ MATERiales de Construcción } \\
\hline & Fachada & Ignimbrita soldada \\
\hline & Muros & Ignimbrita soldada \\
\hline & Techos & Ignimbrita soldada - madera - concreto \\
\hline & Puertas & Madera con alma metálica \\
\hline & Escaleras & Madera - concreto - ignimbrita (enchapados) \\
\hline \multicolumn{3}{|c|}{ ESTADO DE CONSERVACIÓN } \\
\hline & Bueno & $\mathrm{X}$ \\
\hline & Regular & \\
\hline & Malo & \\
\hline \multicolumn{3}{|c|}{ REGISTRO DE RESTAURACIONES } \\
\hline & Físicas & El 13 de octubre de 1926 y en el año 2002 \\
\hline & Adicionales & \\
\hline & Históricas & \\
\hline & Visuales & \\
\hline \multicolumn{3}{|c|}{ OBSERVACIONES } \\
\hline & $\begin{array}{l}\text { Fue objeto de restauraciones } \\
\text { físicas debido a los terremotos }\end{array}$ & \\
\hline \multicolumn{3}{|c|}{ REFERENCIA DOCUMENTAL } \\
\hline & Fuente & Equipo de Investigación de la Universidad Alas Peruanas \\
\hline & Bibliográfica & Arzobispado \\
\hline
\end{tabular}




\section{EL CONVENTO DE SAN FRANCISCO}

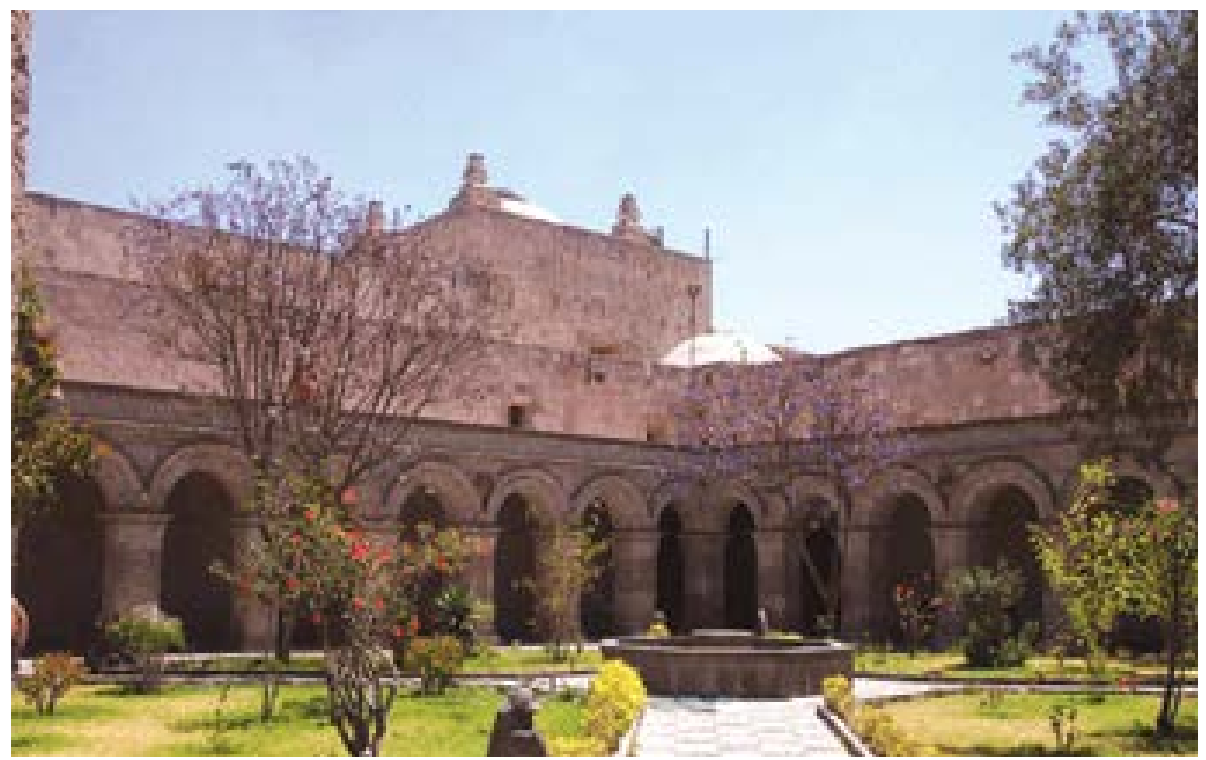

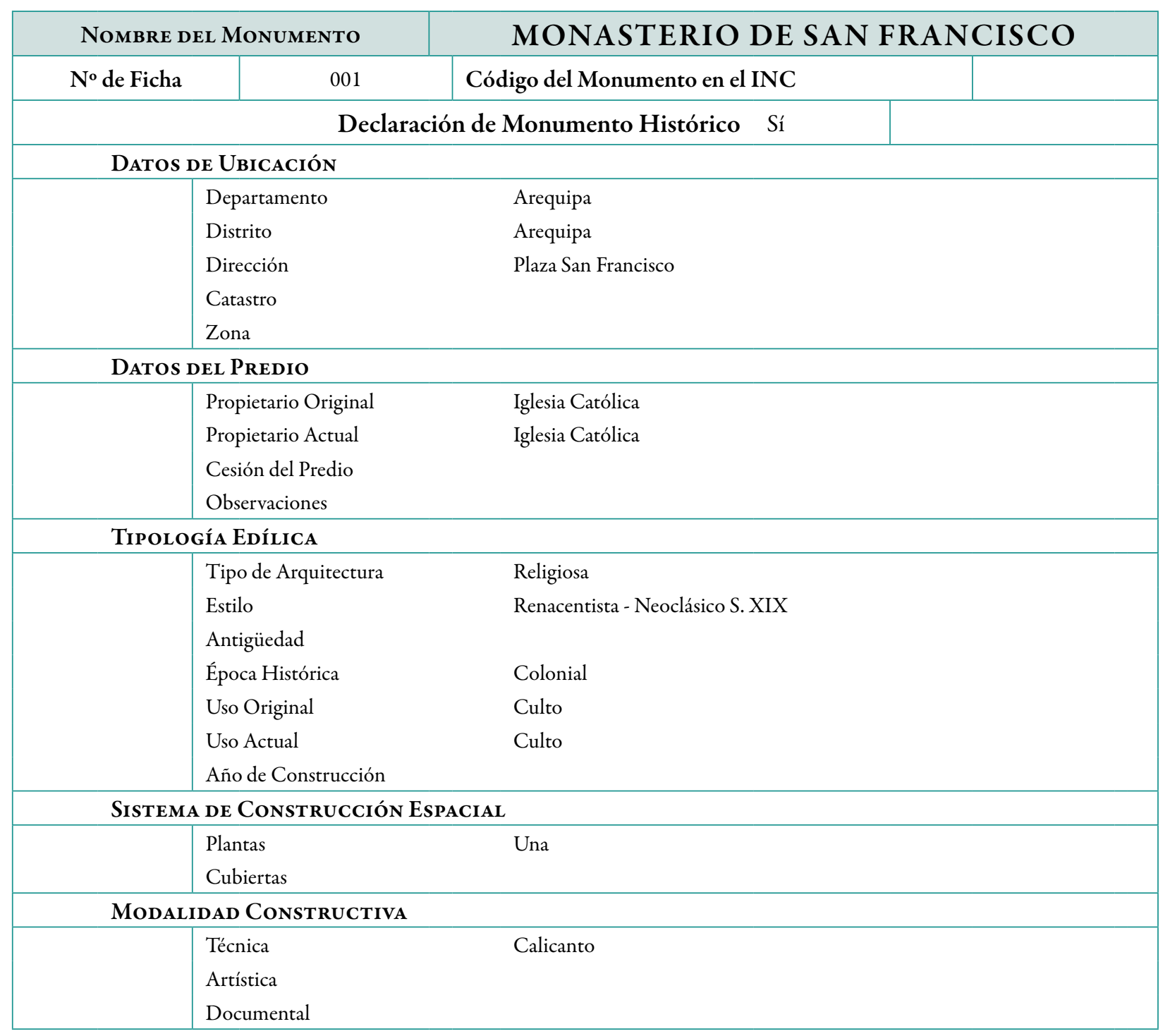




\begin{tabular}{|c|c|c|}
\hline \multicolumn{3}{|l|}{ ÁREAS } \\
\hline & $\begin{array}{l}\text { Número de Pisos } \\
\text { Área Total } \\
\text { Área Construida } \\
\text { Área Libre }\end{array}$ & Uno \\
\hline \multicolumn{3}{|c|}{ Materiales de Construcción } \\
\hline & Fachada & Ignimbrita soldada \\
\hline & Muros & Ignimbrita soldada \\
\hline & Techos & Ignimbrita soldada - madera - concreto \\
\hline & Puertas & Madera con alma metálica \\
\hline & Escaleras & Madera - concreto - ignimbrita (enchapados) \\
\hline \multicolumn{3}{|c|}{ ESTADO DE CONSERVACIÓN } \\
\hline & Bueno & $\mathrm{X}$ \\
\hline & Regular & \\
\hline & Malo & \\
\hline \multicolumn{3}{|c|}{ REGISTRO DE RESTAURACIONES } \\
\hline & Físicas & Año 2002 \\
\hline & Adicionales & \\
\hline & Históricas & \\
\hline & Visuales & \\
\hline \multicolumn{3}{|c|}{ OBSERVACIONES } \\
\hline & $\begin{array}{l}\text { Fue objeto de restauraciones } \\
\text { físicas debido a los terremotos }\end{array}$ & \\
\hline \multicolumn{3}{|c|}{ ReFerencia Documental } \\
\hline & Fuente & Equipo de Investigación de la Universidad Alas Peruanas \\
\hline & Bibliográfica & Arzobispado \\
\hline
\end{tabular}




\section{LA IGLESIA DE LA COMPAÑÍA}

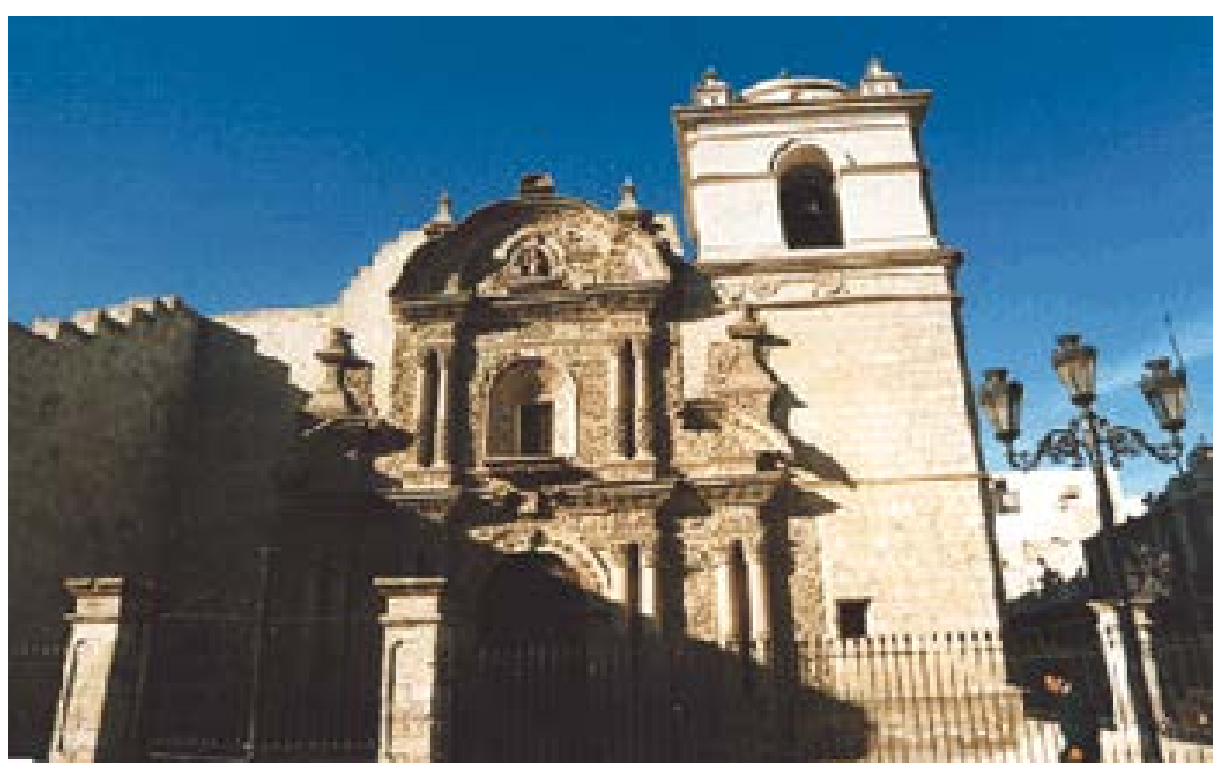

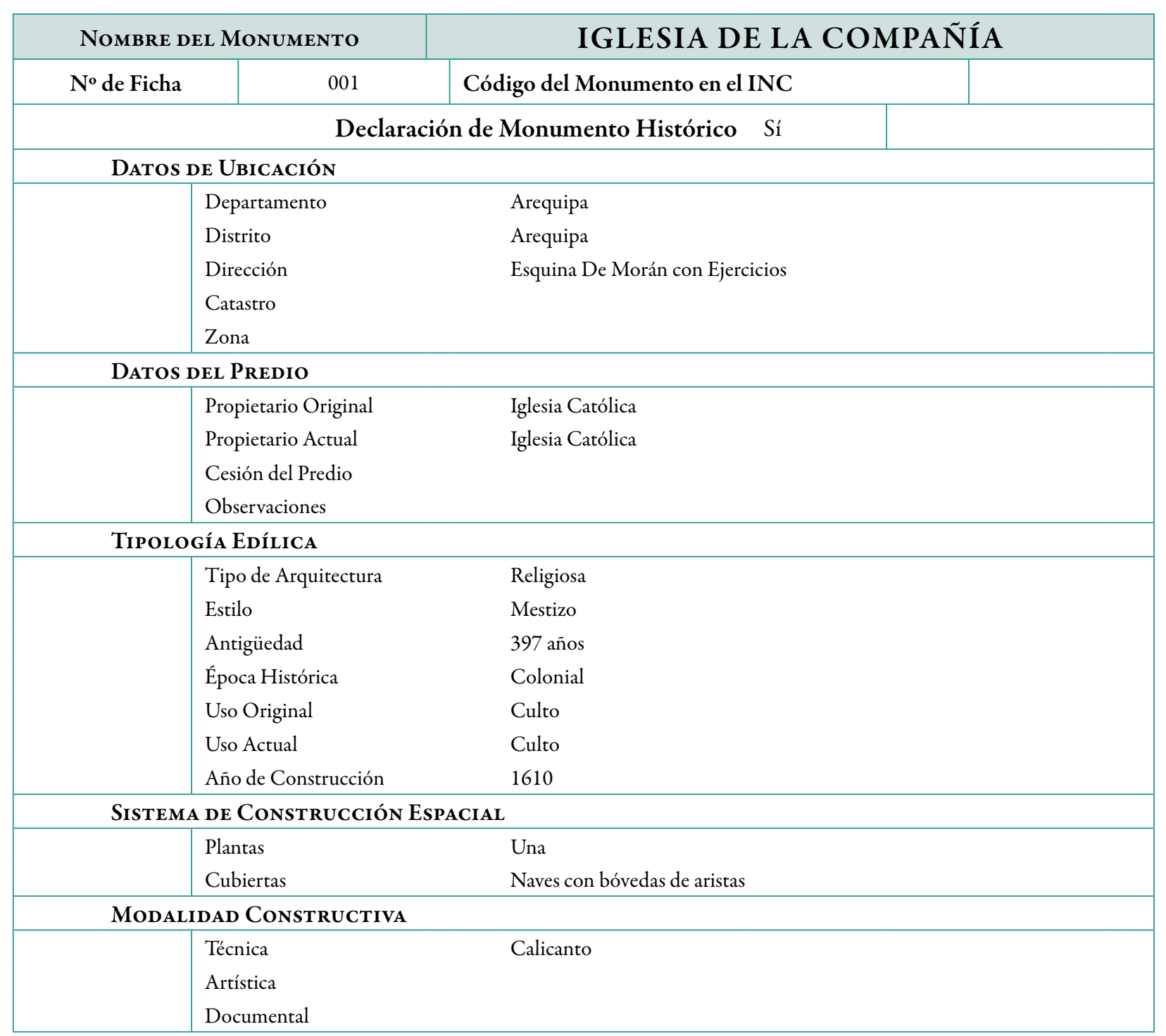




\begin{tabular}{|c|c|c|}
\hline \multicolumn{3}{|l|}{ ÁrEAS } \\
\hline & Número de Pisos & Uno \\
\hline & Área Total & \\
\hline & Área Construida & \\
\hline & Área Libre & \\
\hline \multicolumn{3}{|c|}{ MATERIALES de CONSTRUCCión } \\
\hline & Fachada & Ignimbrita soldada \\
\hline & Muros & Ignimbrita soldada \\
\hline & Techos & Ignimbrita soldada - madera - concreto \\
\hline & Puertas & Madera con alma metálica \\
\hline & Escaleras & Madera - concreto - ignimbrita (enchapados) \\
\hline \multicolumn{3}{|c|}{ ESTADO de CONSERVACIÓN } \\
\hline & Bueno & $\mathrm{X}$ \\
\hline & Regular & \\
\hline & Malo & \\
\hline \multicolumn{3}{|c|}{ REGISTRO DE RESTAURACIONES } \\
\hline & Físicas & Año 2002 \\
\hline & Adicionales & \\
\hline & Históricas & \\
\hline & Visuales & \\
\hline \multicolumn{3}{|c|}{ OBSERVACIONES } \\
\hline & $\begin{array}{l}\text { Fue objeto de restauraciones } \\
\text { físicas debido a los terremotos }\end{array}$ & \\
\hline \multicolumn{3}{|c|}{ ReFerencia Documental } \\
\hline & Fuente & Equipo de Investigación de la Universidad Alas Peruanas \\
\hline & Bibliográfica & Arzobispado \\
\hline
\end{tabular}




\section{LA CASA ARRÓSPIDE}

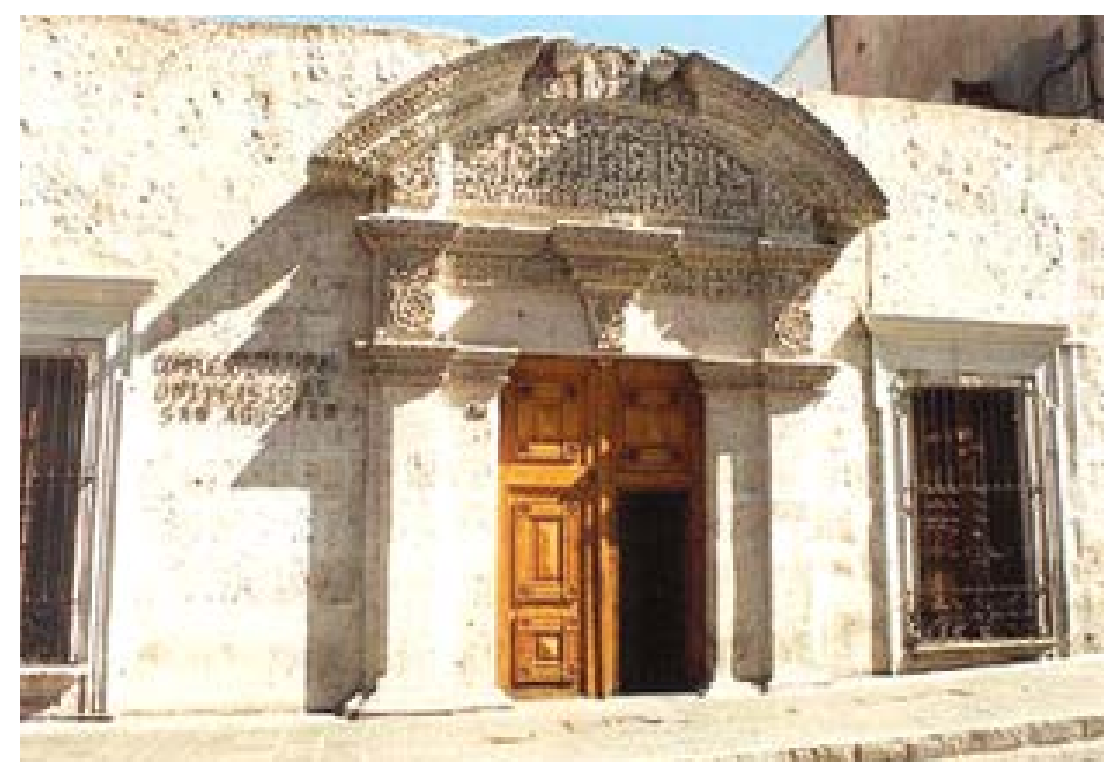

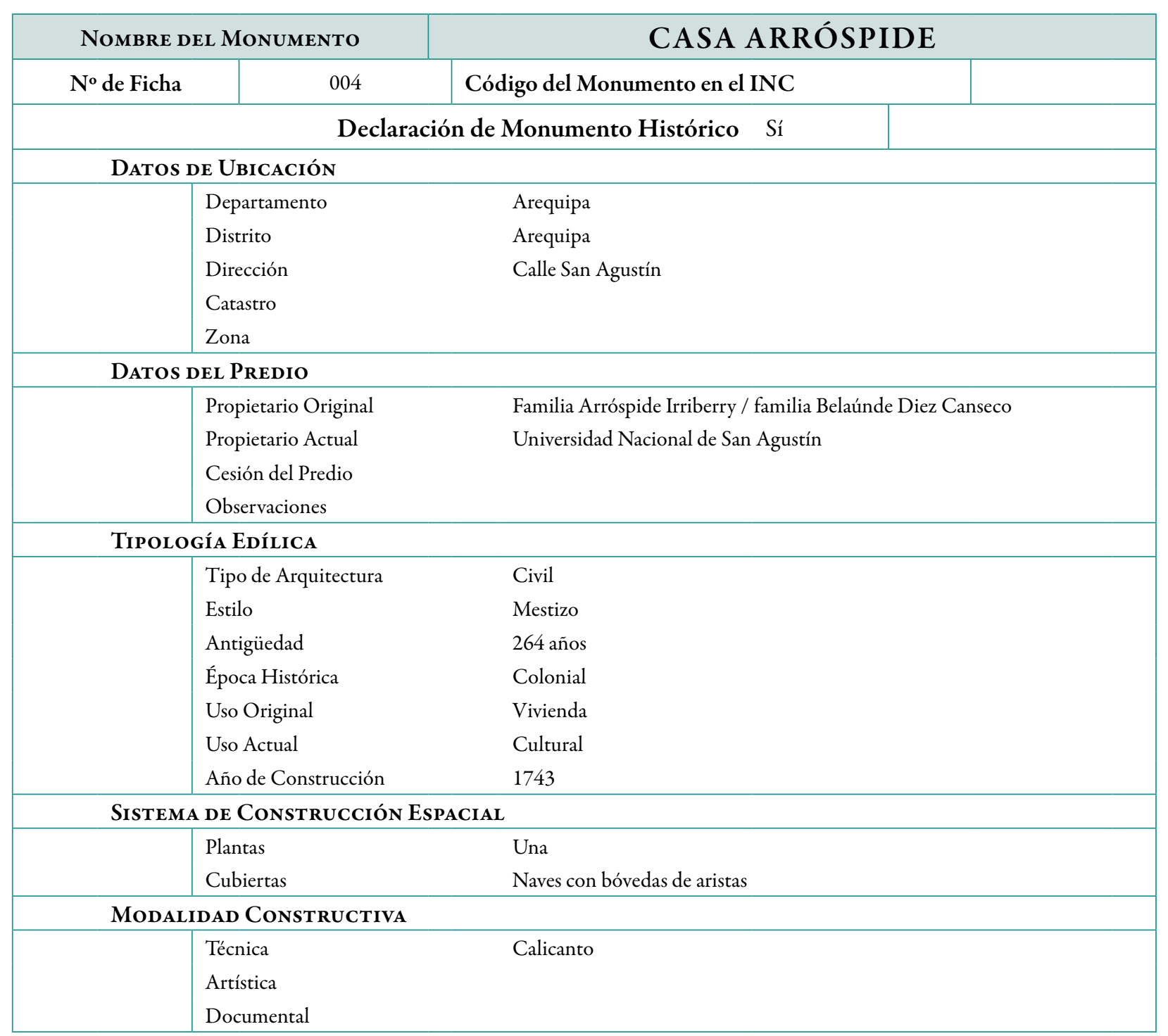




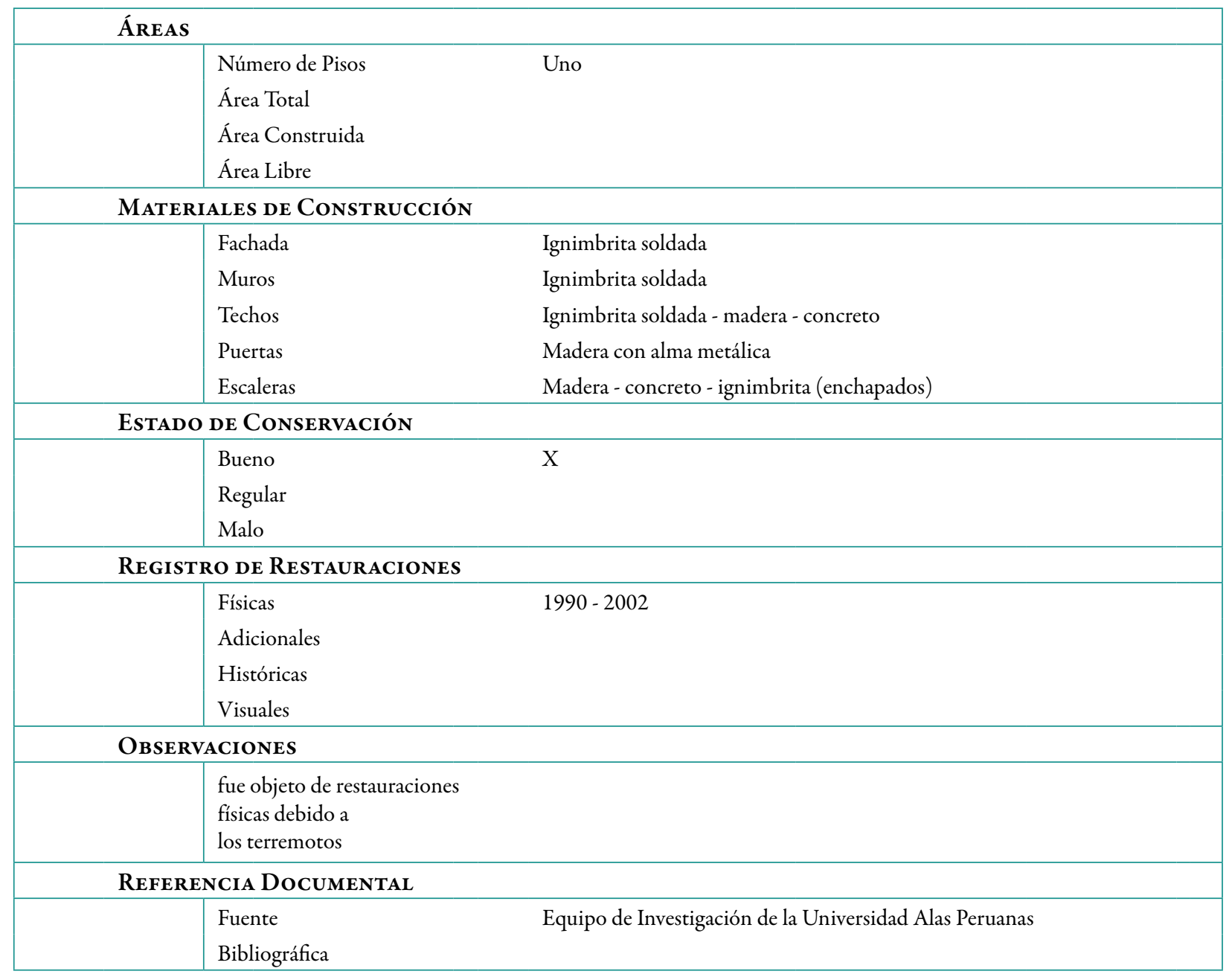




\section{LA CASA GOYENECHE}

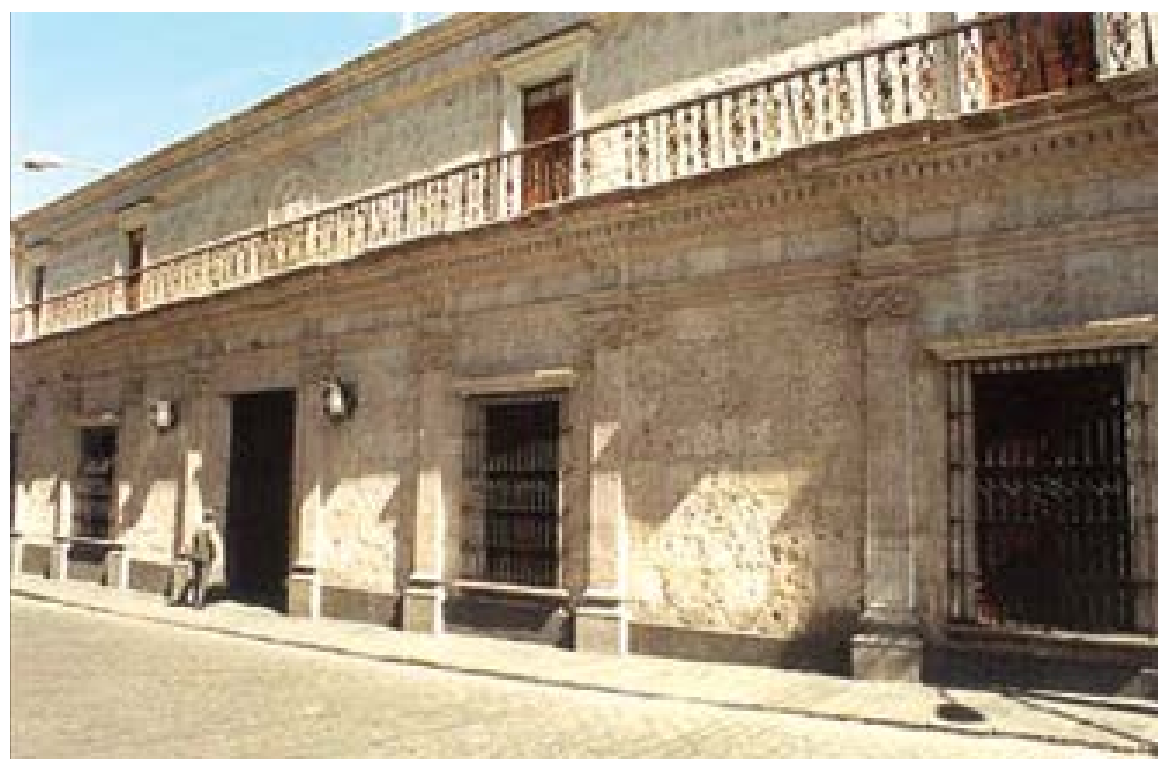

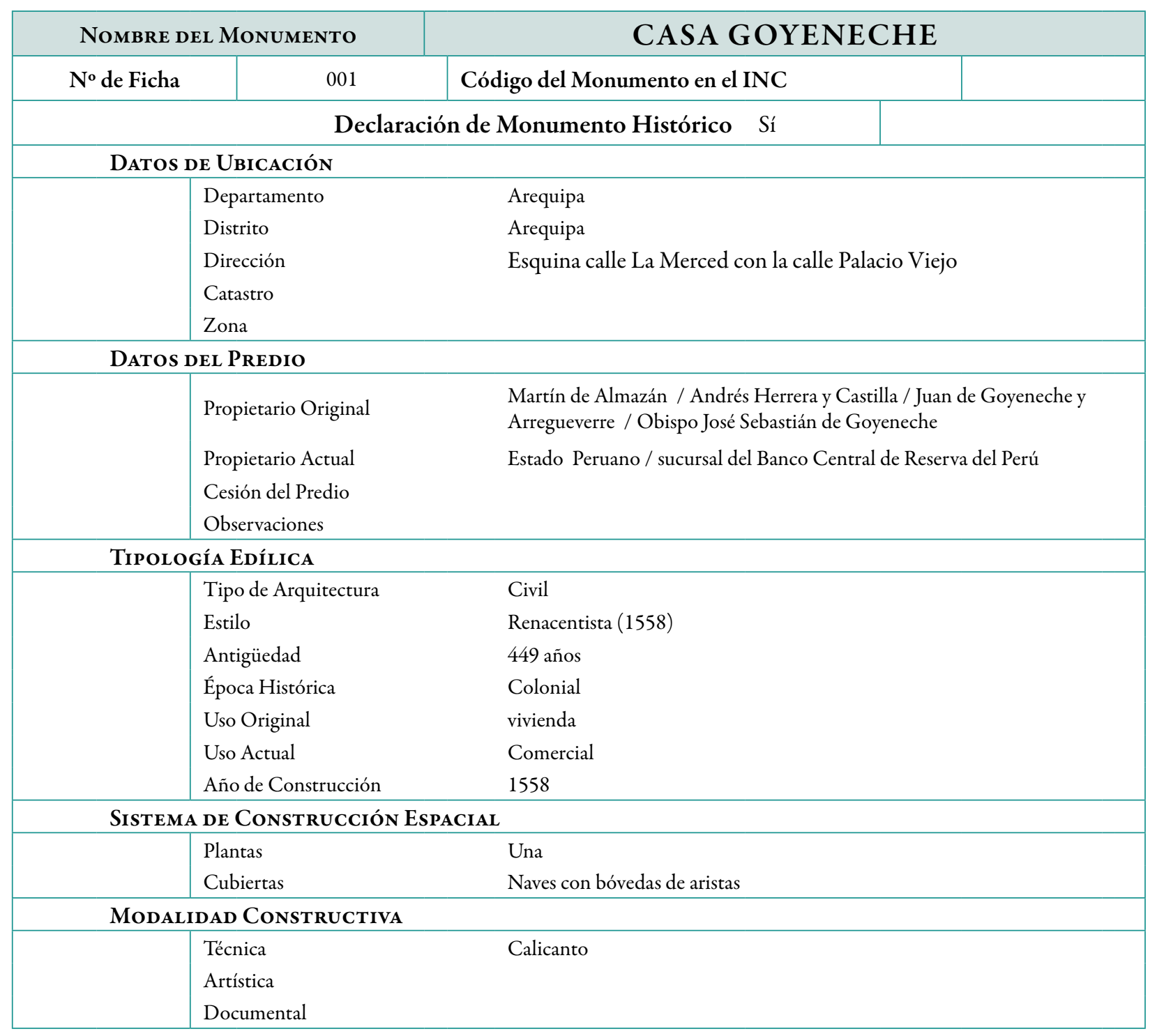




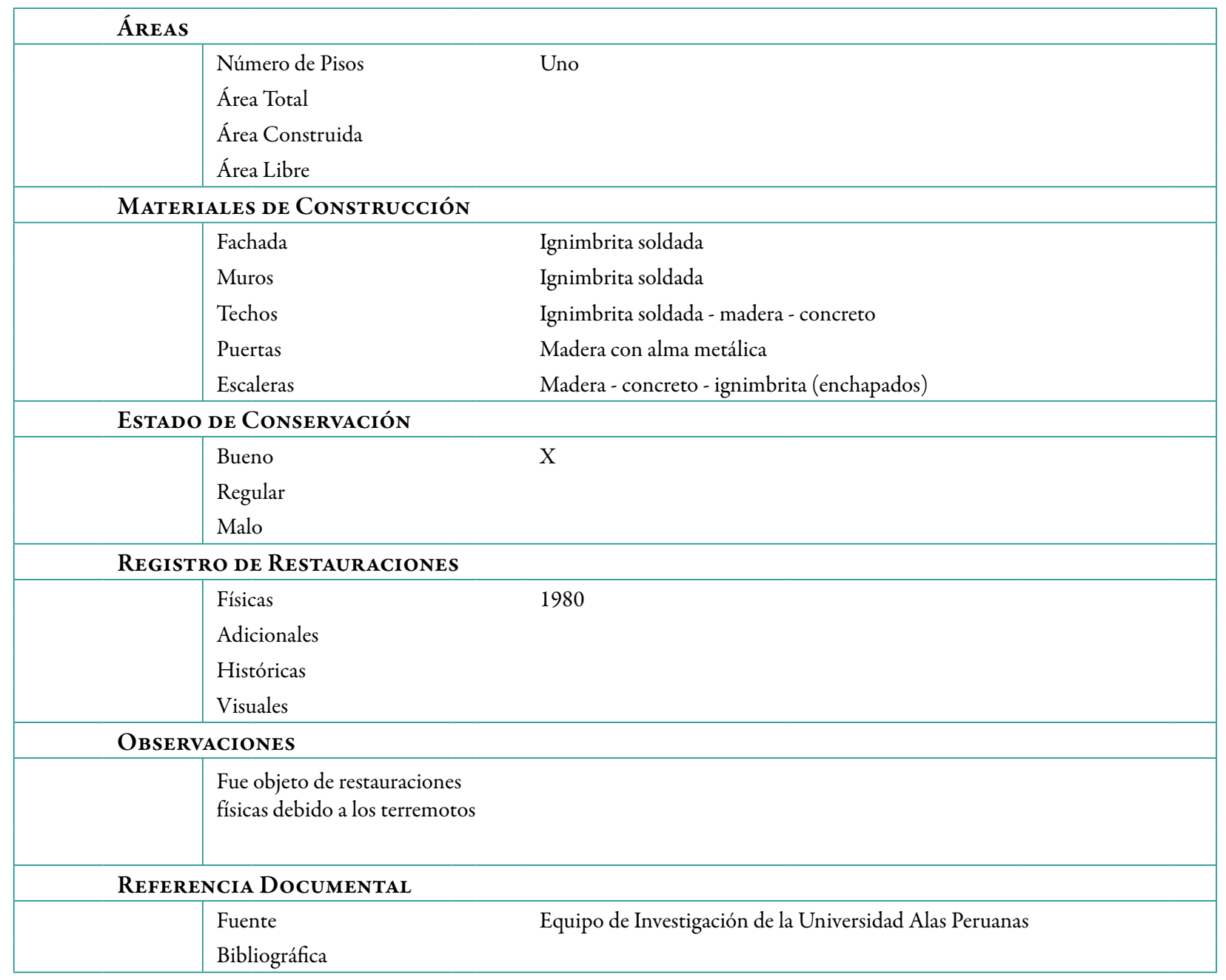




\section{LA CASA TRISTÁN DEL POZO}

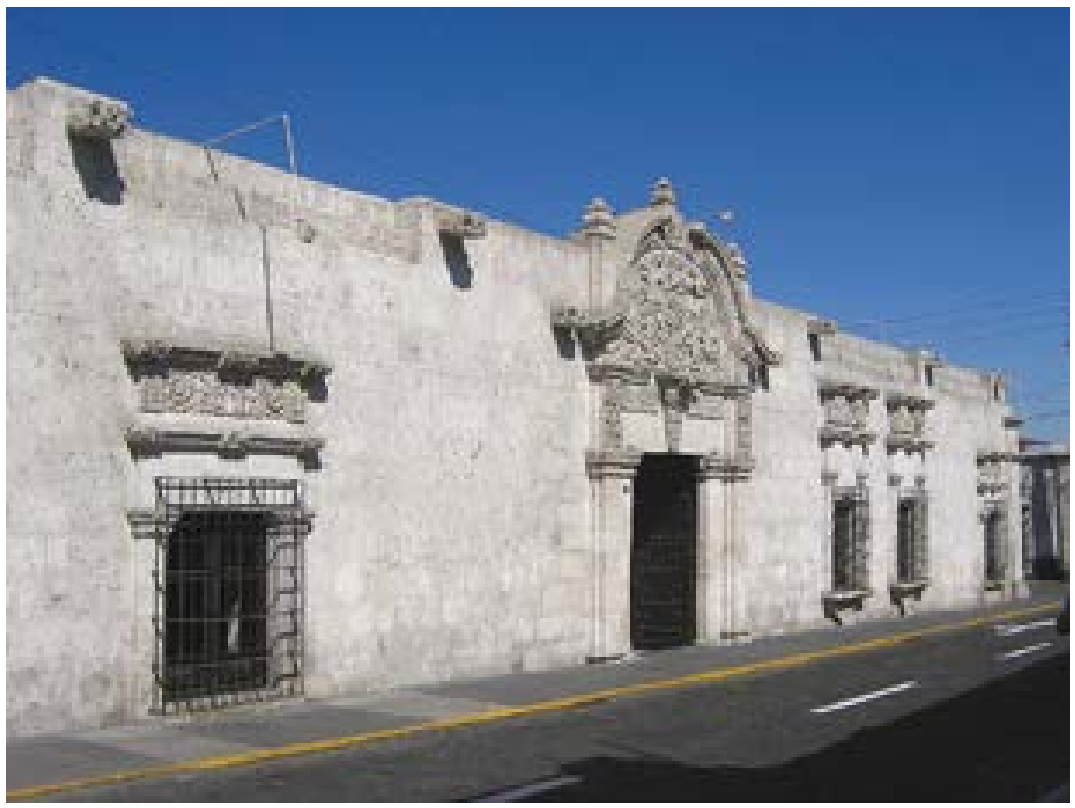

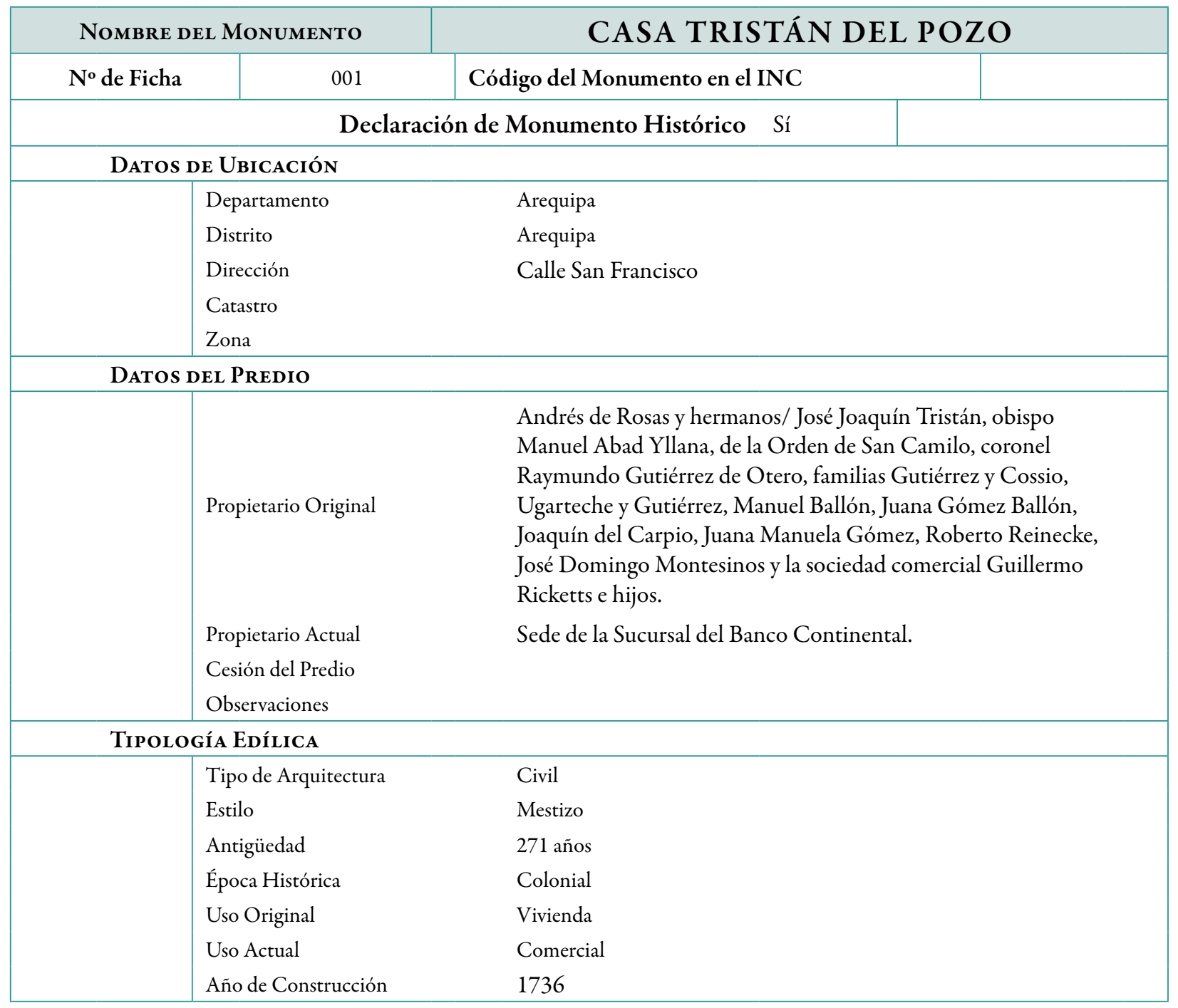




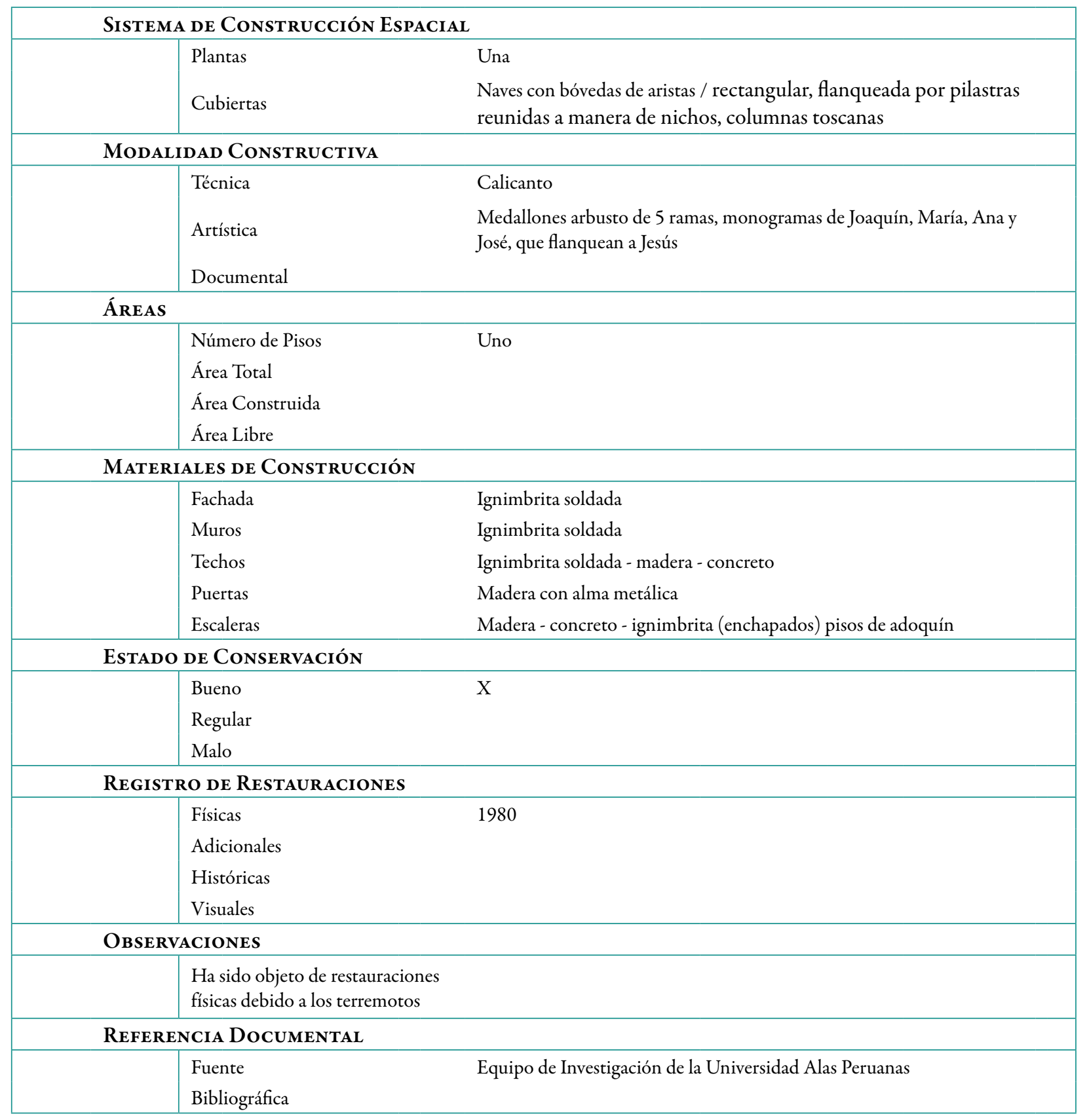




\section{LA CASA DEL DIARIO AREQUIPA AL DÍA}

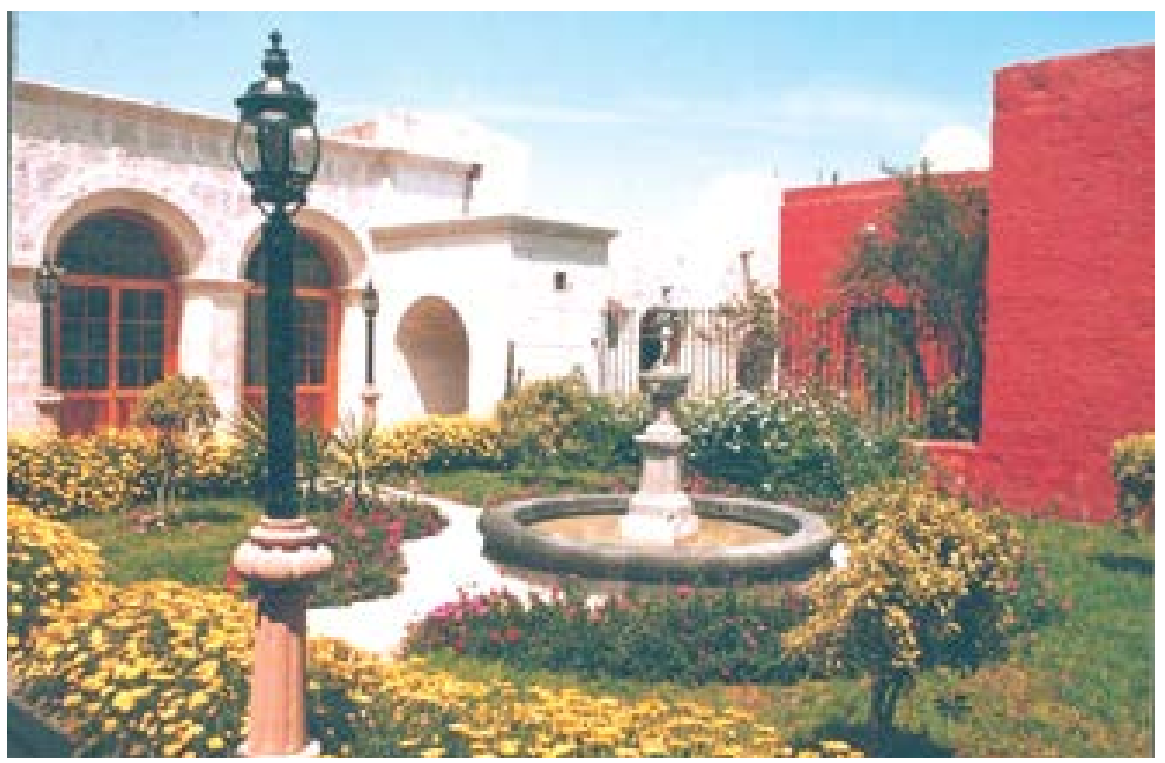

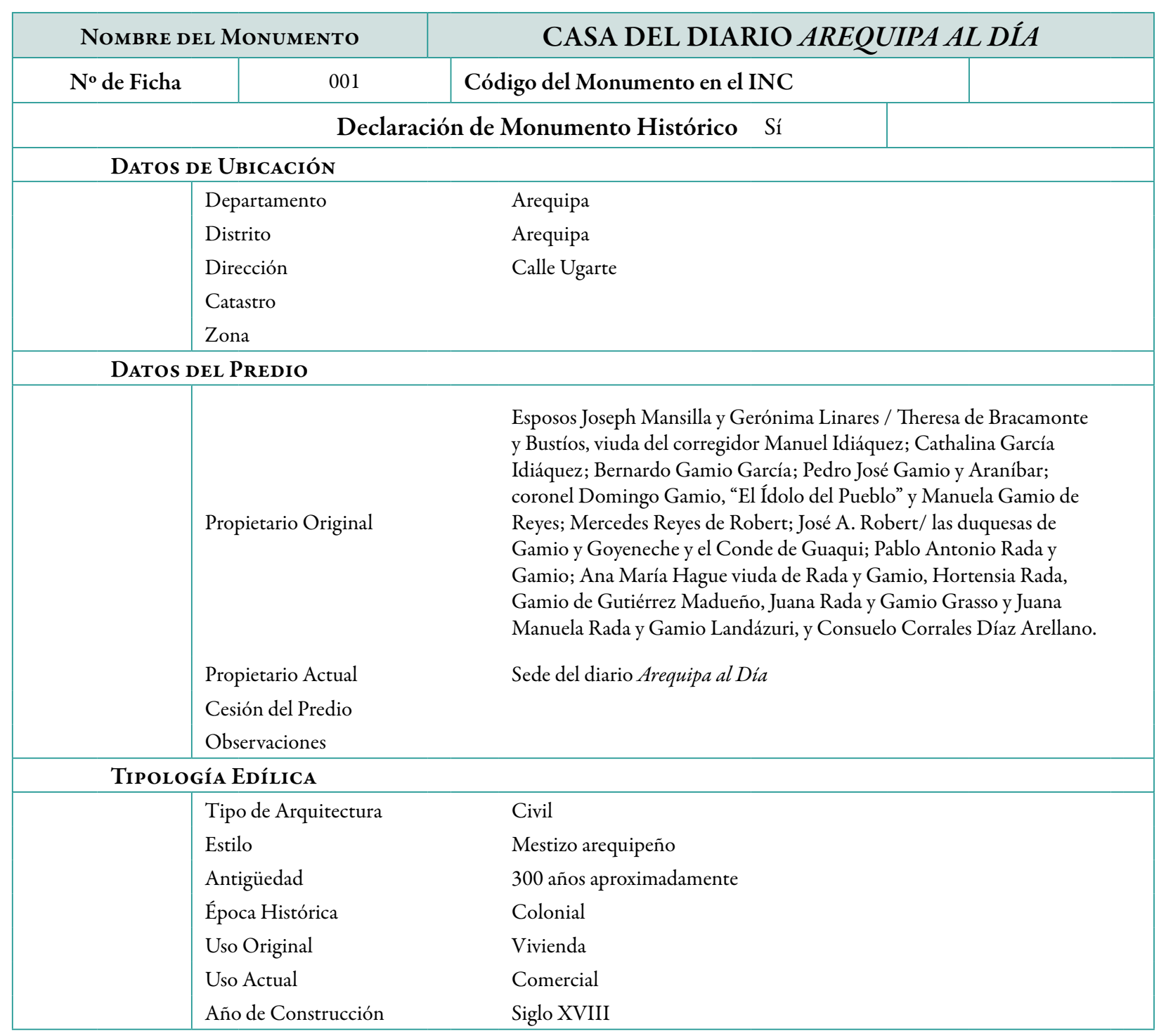




\begin{tabular}{|c|c|c|}
\hline \multicolumn{3}{|c|}{ Sistema de Construcción ESPACial } \\
\hline & Plantas & Una \\
\hline & Cubiertas & \\
\hline \multicolumn{3}{|c|}{ MODAlidad CONSTRUCTIVA } \\
\hline & Técnica & Calicanto \\
\hline & Artística & $\begin{array}{l}\text { Medallones arbusto de } 5 \text { ramas, monogramas de Joaquín, María, Ana y } \\
\text { José, que flanquean a Jesús }\end{array}$ \\
\hline & Documental & \\
\hline \multicolumn{3}{|c|}{ ÁREAS } \\
\hline & Número de Pisos & Uno \\
\hline & Área Total & Mil novecientos metros cuadrados \\
\hline & Área Construida & $\begin{array}{l}\text { Numerosas habitaciones edificadas y reedificadas en distintos } \\
\text { momentos, manteniendo el estilo propio de la arquitectura colonial } \\
\text { arequipeña. }\end{array}$ \\
\hline & Área Libre & Cinco patios, huertas y jardines \\
\hline \multicolumn{3}{|c|}{ MATERiales de Construcción } \\
\hline & Fachada & Ignimbrita soldada \\
\hline & Muros & Ignimbrita soldada \\
\hline & Techos & Ignimbrita soldada - madera - concreto \\
\hline & Puertas & Madera con alma metálica \\
\hline & Escaleras & Madera - concreto - ignimbrita (enchapados) pisos de adoquín \\
\hline \multicolumn{3}{|c|}{ ESTADO DE CONSERVACIÓN } \\
\hline & Bueno & $\mathrm{X}$ \\
\hline & Regular & \\
\hline & Malo & \\
\hline \multicolumn{3}{|c|}{ REgISTRO DE RESTAURACIONES } \\
\hline & Físicas & 1997 \\
\hline & Adicionales & \\
\hline & Históricas & \\
\hline & Visuales & \\
\hline \multicolumn{3}{|c|}{ OBSERVACIONES } \\
\hline & $\begin{array}{l}\text { Sufrió restauraciones físicas } \\
\text { debido a restauraciones y } \\
\text { terremotos }\end{array}$ & \\
\hline \multicolumn{3}{|c|}{ REFERENCIA DOCUMENTAL } \\
\hline & $\begin{array}{l}\text { Fuente } \\
\text { Bibliográfica }\end{array}$ & Equipo de Investigación de la Universidad Alas Peruanas \\
\hline
\end{tabular}

